\title{
MANAGEMENT OF FRACTURE SHAFT HUMERUS WITH DYNAMIC COMPRESSION PLATE AND SCREWS
}

D. Venkateswara Rao¹, Chinta Shyam Kumar², Anvesh Sangepu ${ }^{3}$

\section{HOW TO CITE THIS ARTICLE:}

D. Venkateswara Rao, Chinta Shyam Kumar, Anvesh Sangepu. "Management of Fracture Shaft Humerus with Dynamic Compression Plate and Screws". Journal of Evolution of Medical and Dental Sciences 2015;

Vol. 4, Issue 66, August 17; Page: 11546-11550, DOI: 10.14260/jemds/2015/1664

\begin{abstract}
Fractures of humerus shaft encountered by orthoopaedic surgeon accounting for approximately $3 \%$ of all fractures. Treatment of these injuries continues to evolve as advanced in both non-operative and operative management. It has been generally agreed that must fractured of humeral shaft are treated non- operatively, although occasionally there are indications for primary or secondary operative treatment. Isolated fracture caused by low energy impact are best treated by non-operative treatment, while fracture caused by high-energy trauma require operative management. We treated 50 cases of humerus shaft fractures with open reduction and internal fixation by using Dynamic Compression Plates and screws at Government General Hospital, Vijayawada from May 2012 to April 2015. In our study excellent results were obtained in 30 cases, good results in 16 cases and fair results in 4 cases.
\end{abstract}

KEYWORDS: Humerus shaft fracture, Dynamic compression plate.

INTRODUCTION: Fractures of humerus shaft encountered by orthopedic surgeon accounting for approximately $3 \%$ of all fractures. Treatment of these injuries continues to evolve as advanced in both non-operative and operative management. It has been generally agreed that must fractured of humeral shaft are treated non- operatively, although occasionally there are indications for primary or secondary operative treatment. Isolated fracture caused by low energy impact are best treated by non-operative treatment, while fracture caused by high-energy trauma require operative management.

Union in all cases by conservative form of treatment, complex muscle forces produce bending stresses, which result in angular deformities. Distraction at fracture site and poor opposition noted frequently in conservative management results in delayed union and nonunion, this in turn results in prolonged duration of immobilization thereby producing joint stiffness of elbow and shoulder. Loss of range of movements in upper limb severely impairs ones functional capabilities. Surgical benefits of anatomical alignment, rigid fixation and early rehabilitation are of at most importance to avoid fracture disease Muller et al. ${ }^{1}$

The encouraging results that have been reported with recent advances in internal fixation techniques and instrumentation have led to an expansion of surgical indications for such fractures. Indications for surgical management include open fractures, segmental fractures, bilateral fractures, floating elbow injuries, fractures associated with progressive neurological and fractures in patients with multiple injuries. The contentions of lane are sound and have proved beyond question that when indicated and well done the operative treatment of fractures has given best results.

AIM OF THE STUDY: To analyse the clinical and radiological outcome of fracture shaft humerus treated with Dynamixc compression plate and screws. 


\section{REVIEW OF LITERATURE:}

1. 1956, Laing. ${ }^{2}$ The blood supply to humerus is probably the most important single factor in relation to delayed union. The main nutrient artery enters the bone at the junction of middle and lower third or in the lower part of the middle third.

2. 1963, Muller Ali Gower and others of the A.O. group designed a compression plate and equipment to apply compression force at the fracture site. ${ }^{3}$

3. 1966, klenerman concluded most humeral shaft fractures can be managed by the simple splintage. An anterior bowing of $20^{\circ}$ and varus of $30^{\circ}$ was present before it became clinically obvious and even then functional of limb was good. 4

4. 1977, Sarmiento described functional bracing. ${ }^{5}$

5. 1981, Fredric H: Pollock M.D. et al, studied 24 patients of humeral shaft fractures associated with radial nerve injuries. Concluded, careful observation for return of nerve function and exploration at 3 and half to 4 months after injury, if there is still no clinical and electro myographic evidence of recovery at that time. 6

6. 1982, Hall and Pankovich reported a series of 89 humeral fractures stabilized with Ender nails with 99\% union rate'. They concluded that closed intramedullary Ender nailing could be performed safely in selected fractures of shaft of humerus. ${ }^{7}$

7. 1985, Bell and et al reported 39 humeral shaft fractures in in patients with multiple injuries stabilized using plates and screws. The author concluded that plate fixation of humeral shaft fractures results in excellent rate of osseous union. ${ }^{8}$

8. 1985, Foster et al summarized the advantages and disadvantages of plate fixation and flexible intramedullary nailing. ${ }^{9}$

9. 1993, M. Ingman et al used modified 9mm, tibial nail for fixation of humeral fractures with results better than other methods. ${ }^{10}$

10. 1998, Jose Luis et al intramedullary fixation of pathological fractures improves quality of operation by controlling pain for most patients. ${ }^{11}$

MATERIALS AND METHODS: The present study consisted of 50 patients with displaced fracture of humerus treated with open reduction and internal fixation using plate and screws in Government General Hospital, Vijayawada from May 2012 to April 2015.In this series there are 32 male patients $64 \%$ and 18 female patients 36\%. Age incidence varied from 20 years to 45 years. 36 fractures are right side and 14 fractures are of left sided. 46 fractures were simple and 4 fractures were compound in nature.

The duration between the occurance of injury to internal fixation varied from 7-15 days. In 46 patients humerus is exposed by posterior approach, in 4 patients humerus is approached by anterolateral method.

OBSERVATIONS: In our study, we have treated 50 patients with displaced fracture of humerus shaft by open reduction and internal fixation using Dynamic compression plate and screws. In our study, among 50 patients $32(64 \%)$ were males and $18(36 \%)$ were females. In our study, 20(40\%) patients were between 21-30 years of age, 20(40\%) patients were between 31-40 years of age and 10(20\%) patients were between $41-50$ years of age. Of these 50 patients, $46(92 \%)$ cases were simple fractures and $4(8 \%)$ cases were compound fractures. 
In our study, $16(28 \%)$ cases were left sided an $34(72 \%)$ cases were right sided. Of these 50 cases treated, 4 cases were developed superficial infection which were subsided with intravenous antibiotics. No non-union or no case of refracture was seen among 50 cases. In our study, among 50 cases, 4(8\%) cases were developed Neuropraxia of radial nerve, which were recovered in 6 weeks of post-operative period. In our study, among 50 cases excellent results were obtained in $30(60 \%)$ cases, good results in $16(32 \%)$ cases and fair results in $4(8 \%)$ cases.
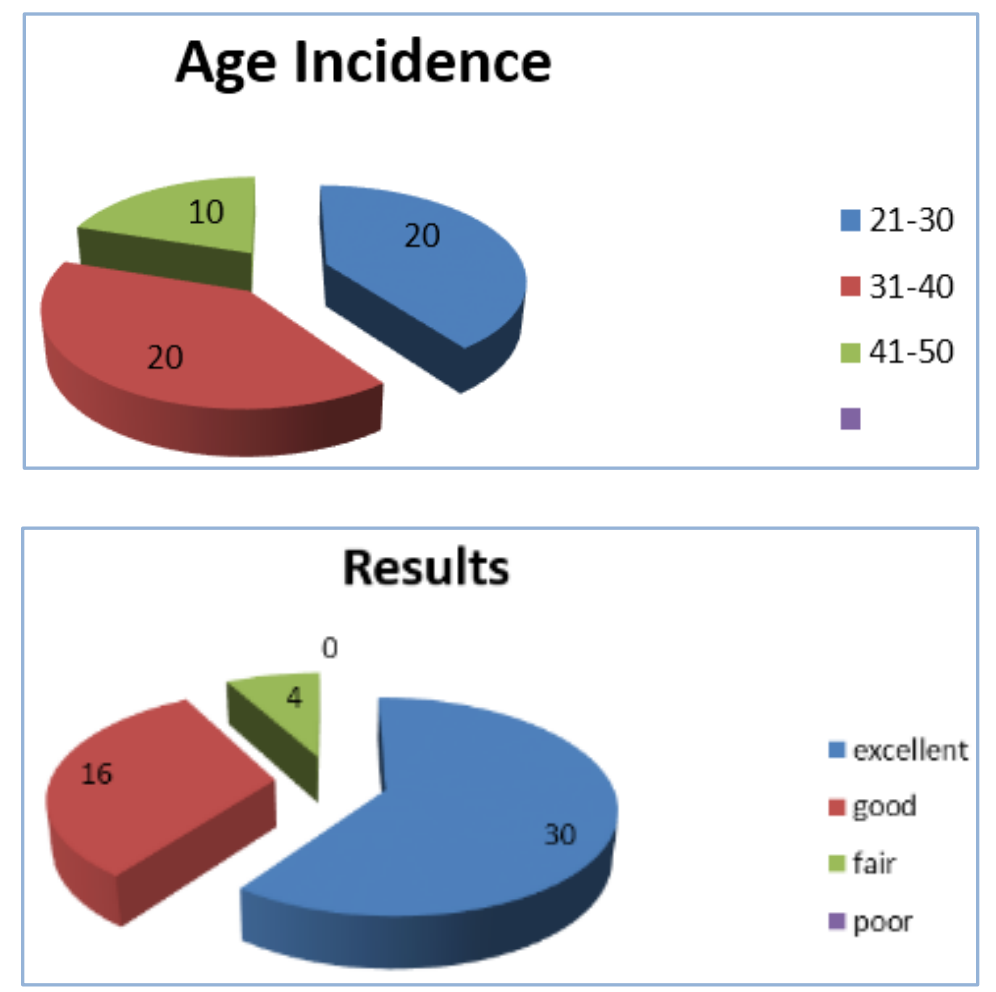

DISCUSSION: Our study included 50 cases fracture humerus shaft treated in Government General Hospital, Vijayawada with open reduction and internal fixation of humerus shaft fracture with Dynamic compression plate and screws. On further analysis by doing an open reduction and internal fixation with D.C.P. and screws the reduction is anatomical and it avoids rotational deformities. The other advantage with this process is early physiotherapy with the movement at the shoulder and at the elbow at the end of the treatment of 8 weeks to 12 weeks, the patient is in absolute fit condition to go back to his routine work.

\section{This Line of Treatment Differs from the Conservative Line of Treatment by:}

1. Absolute anatomical reduction.

2. Restoration of movements and functions to the normally in early stage.

3. No complications of fracture disease.

Our method has more advantages than those fractures which were treated by open reduction and internal fixation by intramedullary nail or rush pin either from above or below. In this method immobilization is longer and there is a possibility for rotational movements occurring at fracture site. So, the advantage of internal fixation is lost, as you cannot give early mobilization. 
Fracture shaft humerus treated conservatively required prolonged immobilization and to restore for the normal function it look long time comparatively to ORIF with DC plate and screws. By doing ORIF there is another advantage that we can repair or examine the radial nerve which was infrequently affected with this fracture.

Muller et al (1979) has advocated that compression to the fractures produced with rigid fixation gives opportunity for early mobilization and physiotherapy and early union at the fracture site. Stewart and hundley J. M. have studied 96 cases of fracture humerus. Half of them were treated conservatively. Of these treated conservatively, $69 \%$ cases were obtained unsatisfactory results from either non-union of loss of movements due to prolonged immobilization.

Complications in our study are infection in 4 cases, neuropraxia of radial nerve in 4 cases. Infection was mild, superficial and was controlled in 10 days time. Neuropraxia recovered in 6 weeks.

We conclude and confirm our elder's statement, Eggers, Burrwell and Charnely that open reduction and rigid fixation with plate and screws to the shaft of humerus has more advantageous and beneficial to the patient.

\section{CONCLUSION:}

1. Open reduction and internal fixation for fracture of humerus in adults is always better than conservative management.

2. Rigid fixation with Dynamic compression plate (DCP) and screws has shown to give good results.

3. Repeated manipulation has no place in the treatment of fracture of humerus in the adults.

4. A DCP of longer length is preferred.

5. Rigid fixation cannot be obtained by intramedullary nails.

6. Complications of open reduction are few and are avoidable if proper care is adopted.

7. Open reduction and internal fixation with A.O. plating technique is an excellent mode of management of transverse and short oblique fracture pattern, asceptic delayed union, nonunion, fractures with failed closed methods of reduction due to soft tissue inter position and fractures with primary and secondary nerve palsy.

\section{REFERENCES:}

1. Muller, M.E., Nazarian, S. Koch, P., and Schatzker, J: The comprhensive Classification of Fractures of Long Bones. Berlin, Springer-Verlag. 1990.

2. Laing P: The arterial supply of the Adult Humerus, J. Bone Joint Surgery, 38A: 1105, 1956.

3. Muller M. Allgower, R Schneider, H. Willengger. Manual of Internal Fixation, Techniques Recommended by AO-ASIF Group, 3rd edition.

4. Klenerman, L: Experimental Fractures of the Adult Humerus, Med. Boil. Eng, 7:356-364, 1969.

5. Sarmiento, A. Horowich, A. Aboulfia, A and Vangness, C. T. Jr: Functional Bracing for Comminuted Extra articular Fractures of the Distal Third of the Humerus. J. Bone Joint surgery, 72, B: 283; 287; 1990.

6. Pollock, F.H. Drake, D.Bovill, E.G., Day, L, and Trafton, P. G.: Treatment of Radial Neuropathy Associated with Fractures of The Humerus. J. Bone Joint surgery, 63A: 239-243, 1981.

7. Hall, R.F., Jr. and Pankovich, A.m.: Ender nailing of Acute Fractures of The Humerus: A study of closed Fixation by intramedullary nails without reaming. J. Bone Joint surgery, 69A: 559-567, 1987. 
8. Bell M. J., Beauchamp, C. G. kellam, J.K. and Mc. Murthy, R. Y. The result of plating humeral shaft fractures in patient with multiple injuries: The Sunnybrok- Experiences. J. Bone Joint surgery, 67B:296, 1985.

9. Foster, R.J. Dixon, G. L Bach, A.W., Appleyard, R. W. and Green T. M. internal Fixation of Fractures and Non-union of the Humeral Shaft indications and Results in a Multi-Center Study. J. Bone Joint surgery, 67A: 857-864, 1985.

10. Ingman A. M. and Waters, D.A.: locked intramedullary nailing of humeral shaft fractures: Implant design, Surgical Technique, and Clinical results. J. Bone Joint surgery, 76B:23-29, 1994.

11. Jose Luis Tome et al: Treatment of Pathological fracture of humerus with sideal Nailing CoRR 350. PP51-55: 1998.

\section{AUTHORS:}

1. D. Venkateswara Rao

2. Chinta Shyam Kumar

3. Anvesh Sangepu

\section{PARTICULARS OF CONTRIBUTORS:}

1. Associate Professor, Department of Orthopaedics, Siddhartha Medical College/Government General Hospital, Vijayawada.

2. Associate Professor, Department of Orthopaedics, Siddhartha Medical College/Government General Hospital, Vijayawada.

FINANCIAL OR OTHER COMPETING INTERESTS: None
3. Post Graduate, Department of Orthopaedics, Siddhartha Medical College/Government General Hospital, Vijayawada.

\section{NAME ADDRESS EMAIL ID OF THE} CORRESPONDING AUTHOR:

Dr. D. Venkateswara Rao,

M.S. (Ortho), M.Ch.(Ortho) U.K. $4^{\text {th }}$ Lane, Subba Rao Colony,

Flat No. 76, House. No. 54/20/2-7A, Ladies Hostel, Near Gurudwar Temple, Gurunanak Colony, Vijayawada-520008.

E-mail: d_yenkee@yahoo.com

Date of Submission: 07/08/2015.

Date of Peer Review: 08/08/2015.

Date of Acceptance: 12/08/2015.

Date of Publishing: 17/08/2015. 